\title{
Molecular genetic analysis and growth hormone response in patients with syndromic short stature
}

\author{
Huihui Sun ${ }^{1}, \mathrm{Na} \mathrm{Li}{ }^{2}$ and Naijun Wan ${ }^{1 *}$
}

\begin{abstract}
Background: Syndromic short stature is a genetic and phenotypic heterogeneous disorder with multiple causes. This study aims to identify genetic causes in patients with syndromic short stature of unknown cause and evaluate the efficacy of the growth hormone response.
\end{abstract}

Methods: Trio-whole-exome sequencing was applied to identify pathogenic gene mutations in seven patents with short stature, multiple malformations, and/or intellectual disability. Whole-genome low-coverage sequencing was also performed to identify copy number variants in three patients with concurrent intellectual disability. Recombinant human growth hormone was administered to improve height in patients with an identified cause of syndromic short stature.

Results: Of the seven patients, three pathogenic/likely pathogenic gene mutations, including one FGFR3 mutation (c.1620C >A p.N540K), one novel GNAS mutation (c.2288C > T p.A763V), and one novel TRPS1 mutation (c.2527_c.2528dupTA p.S843fsX72), were identified in three patients. No copy number variants were identified in the three patients with concurrent intellectual disability. The proband with an FGFR3 mutation, a female 4 and 3/12 years of age, was diagnosed with hypochondroplasia. Long-acting growth hormone improved her height from $85.8 \mathrm{~cm}$ [-5.05 standard deviation (SD)] to $100.4 \mathrm{~cm}(-4.02 \mathrm{SD})$, and her increased height SD score (SDS) was 1.03 after 25 months of treatment. The proband with a GNAS mutation, a female 12 and 9/12 years of age, was diagnosed with pseudohypoparathyroidism la. After 14 months of treatment with short-acting growth hormone, her height improved from $139.3 \mathrm{~cm}(-2.69 \mathrm{SD})$ to $145.0 \mathrm{~cm}(-2.36 \mathrm{SD})$, and her increased height SDS was 0.33 .

Conclusions: Trio-whole-exome sequencing was an important approach to confirm genetic disorders in patients with syndromic short stature of unknown etiology. Short-term growth hormone was effective in improving height in patients with hypochondroplasia and pseudohypoparathyroidism la.

Keywords: Syndromic short stature, Trio-whole-exome sequencing, Whole-genome low-coverage sequencing, FGFR3, GNAS, TRPS1

*Correspondence: wann6971@163.com

1 Department of Paediatrics, Beijing Jishuitan Hospital, No. 31 of Xinjiekou Dongjie Street, Xi Cheng District, Beijing 100035, People's Republic of China

Full list of author information is available at the end of the article

\begin{abstract}
Background
Syndromic short stature is a phenotypic and genetically heterogeneous disease with a complex aetiology, including chromosomal aberrations, copy number variants (CNVs), gene mutations, methylation defects and other unknown causes [1]. Given the diversity and rarity of these disorders, precision diagnosis is difficult based on
\end{abstract}


clinical manifestations and laboratory and radiological examination findings [2]. Molecular genetic analysis plays an important role in the precision diagnosis, proper treatment, prognosis, and genetic counselling of patients with short stature of unknown aetiology [3]. Recombinant human growth hormone (rhGH) use has been advocated in patients with Turner syndrome, Prader-Willi syndrome, and Noonan syndrome [4-6]. However, rhGH use is not routine in patients with many other syndromic short statures.

In our study, trio-whole exome sequencing (TrioWES) was used to identify pathogenic gene mutations in patients with syndromic short stature of unknown aetiology [7]. Whole-genome low-coverage sequencing was also carried out to identify CNVs in patients with syndromic short stature combined with intellectual disability [8, 9]. The study describes the clinical manifestations, radiological examination and gene mutation analysis findings and rhGH treatment responses in patients with syndromic short stature.

\section{Methods \\ Patients}

Patients were referred to the paediatric department of Beijing Jishuitan Hospital from March 2017 to December 2019. The criteria for the diagnosis of syndromic short stature were as follows [10-12]: height two standard deviations (SDs) below the mean of healthy Chinese children adjusted for age and sex; the presence of multiple malformations; and/or intellectual disability. The exclusion criteria were as follows: chronic liver and renal disease and comorbidities that could affect growth. These patients had unrecognized syndromes based on clinical and radiological manifestations. Written informed consent was obtained from the guardians of these patients. Clinical data and peripheral lymphocyte DNA were collected from the probands and their parents. All the probands had normal G-banded karyotyping.

\section{Trio-WES}

Trio-WES was used to identify pathogenic gene mutations in patients with short stature. Genomic DNA was extracted from peripheral blood using the Blood Genome Column Medium Extraction Kit (Kangweishiji, China) according to the manufacturer's instructions. The extracted DNA samples were subjected to quality control using a Qubit 2.0 fluorimeter and electrophoresis with a $0.8 \%$ agarose gel for further protocols. Protein-coding exome enrichment was performed using xGen Exome Research Panel v1.0 (IDT, Iowa, USA), which consists of 429,826 individually synthesized and quality-controlled probes, targeting a $39 \mathrm{Mb}$ protein-coding region (19,396 genes) of the human genome and covering $51 \mathrm{Mb}$ of endto-end tiled probe space. High-throughput sequencing was performed by an Illumina NovaSeq 6000 series sequencer (PE150), and no less than $99 \%$ of the target sequences were sequenced. The sequencing process was performed by Beijing Chigene Translational Medicine Research Center. Raw data were processed quickly for adapter removal and low-quality read filtering. The paired-end reads were performed using BurrowsWheeler Aligner to the Ensemble GRCh37/hg19 reference genome. Base quality score recalibration, together with single nucleotide polymorphisms (SNPs) and short indel calling, was conducted using GATK. According to the sequence depth and variant quality, SNPs and indels were screened, and high-quality and reliable variants were obtained. The online system independently developed by Chigene (www.chigene.org) was used to annotate database-based minor allele frequencies (MAFs) and American College of Medical Genetics (ACMG) practice guideline-based pathogenicity of every yielded gene variant, and the system also provides a serial software package for conservative analysis and protein product structure prediction.

The databases for MAF annotation include the 1000 Genomes, dbSNP, ESP, ExAC, and Chigene in-house MAF databases. The Provean, Sift, Polypen2_hdiv, Polypen2_hvar, MutationTaster, M-Cap, and Revel software packages were used to predict protein product structure variation. As a prioritized pathogenicity annotation to ACMG guidelines, Online Mendelian Inheritance in Man (OMIM), Human Gene Mutation Database (HGMD) and ClinVar databases were used as conferences of pathogenicity of every variant [13]. Sanger sequencing was further used to confirm the candidate variants. The patients' parents were also examined to determine the origins.

\section{Whole-genome low-coverage sequencing}

Whole-genome low-coverage sequencing was performed to identify CNVs in patients with syndromic short stature and intellectual disability. Genomic DNA was extracted from peripheral blood samples and sheared to 200-300 bp fragments by sonication, followed by electrophoresis analysis for quality control. The fragments were then end-repaired and A-tailed in preparation for ligation to adapters. The ligates were amplified by ligation-mediated PCR for 4-6 rounds. High-throughput sequencing was performed on an Illumina NovaSeq 6000 series sequencer (Illumina, San Diego, CA, USA). Raw image files were processed by BclToFastq (Illumina) for base calling and raw data generation. Reads were mapped to reference genome hg19 using BWA software. CNVs of $100 \mathrm{~kb}$ or more in length were detected using Chigene independently developed software packages for $\mathrm{CNV}$ detection. 
$\mathrm{CNV}$ intervals were detected and screened according to public CNV databases and local databases. Decipher, ClinVar, ClinGen, and the Database of Genomic Variants (DGV) were used as references to annotate the pathogenic classification of each screened CNV. The biological harm and related phenotypes of CNVs were assessed by annotated information and frequency databases according to the ACMG practice guidelines and 2011 and 2013 CNV diagnostic guidelines [14, 15].

\section{GH treatment}

GH stimulation tests were performed to confirm whether patients had GH deficiency. Oral clonidine $(4 \mu \mathrm{g} / \mathrm{kg})$ or $10 \%$ arginine $(0.5 \mathrm{~g} / \mathrm{kg}$, maximum dose $30 \mathrm{~g})$ intravenous injection was administered. Then, blood samples were drawn at $0^{\prime}, 30^{\prime}, 60^{\prime}, 90^{\prime}$, and $120^{\prime}$ time points to examine GH concentration. Normal GH was defined as a GH level above $10 \mathrm{ng} / \mathrm{mL}$, partial GH deficiency was defined as a GH level of 5-10 ng/mL, and complete GH deficiency was defined as a GH level below $5 \mathrm{ng} / \mathrm{mL}$. According to the growth pattern and bone age (BA) delay, rhGH (GenSci, China) treatment was initiated to improve height. Patient height and weight were measured and recorded every 3 months. The patient's biochemical parameters, such as liver and kidney functions, myocardial enzymes, blood electrolytes, blood glucose, haemoglobin A1c (HbA1C), insulin (INS) and thyroid function, were also monitored every 3 months. Their BA was examined every six months to one year. The adverse effects of GH therapy, such as headaches, hypertension, arthralgia, liver damage, tumours, hypothyroidism, and diabetes, were carefully noted. GH dosage was adjusted according to the growth velocity and insulin-like growth factor-1 (IGF-1) level.

\section{Results}

All methods were carried out in accordance with relevant guidelines and regulations. Seven patients with syndromic short stature were recruited in this study, as shown in Table 1. In addition to short stature, other features were skeletal dysplasia $(n=7)$, facial dysmorphism $(n=5)$, intellectual disability $(\mathrm{n}=3)$, and congenital heart disease $(\mathrm{n}=1)$. We identified 2 pathogenic mutations (FGFR3, c.1620C $>$ A p.N540K; TRPS1, c.2527_c.2528dupTA p.S843fsX72) and 1 likely pathogenic mutation (GNAS, c. $2288 \mathrm{C}>\mathrm{T}$ p.A763V) in three patients, respectively. All of these mutations were heterozygous and inherited from their affected parents. This FGFR3 mutation has been reported previously, and the two other mutations are novel.

The first proband was a 4- and 3/12-year-old girl. She had short stature and short limbs. She had intellectual disability, persistent hyperplastic primary vitreous
(PHPV) of the right eye, and incontinentia pigmenti. Other clinical manifestations included macrocephaly, lumbar lordosis with protruding abdomen, genu varum, tibial bowing, and joint laxity (Fig. 1). She was born at full term by caesarean section. Her birth weight was $2750 \mathrm{~g}$, and her birth length was unknown. She had no history of perinatal asphyxia. Her height was $85.8 \mathrm{~cm}$ $(-5.05 \mathrm{SD})$, weight was $13.8 \mathrm{~kg}(-1.74 \mathrm{SD})$, and body mass index (BMI) was $18.75 \mathrm{~kg} / \mathrm{m}^{2}$ (2.38 SD). Her head circumference was $53 \mathrm{~cm}$ (2.61 SD). Her upper segment was $51.5 \mathrm{~cm}$, and her lower segment was $34.5 \mathrm{~cm}$. The upper/lower segment ratio was 1.5 (normal: 1.23-1.47). Her radiological features included dorsal concavity of the lumbar vertebrate bodies, widened inferior lumber interpedicular distance, a short and broad femoral neck, short squared ilea, a flattened acetabular roof, and a shortening of the long bones with metaphyseal flare, as shown in Figs. 2 and $3[16,17]$.

Both her father and mother had intellectual disability, with heights of $150 \mathrm{~cm}$ and $151 \mathrm{~cm}$, respectively. A fibroblast growth factor receptor 3 (FGFR3) mutation c.1620C $>$ A (p.N540K) was identified in the proband and her father [18].

$\mathrm{GH}$ provocative tests showed peak concentrations of $8.42 \mathrm{ng} / \mathrm{mL}$ after levodopa and $8.21 \mathrm{ng} / \mathrm{mL}$ after arginine. At presentation, the patient's height was $85.8 \mathrm{~cm}$, $-5.05 \mathrm{SD}$ height for age. Although her chronological age (CA) was 4-3/12 years, her BA was 2.5 years. Before treatment, the mean annual growth velocity of the patient was $3-4 \mathrm{~cm}$. Long-acting GH (polyethylene glycol recombinant human somatropin injection) was initiated as shown in Table 2. After 25 months of treatment, her height improved to $100.4 \mathrm{~cm},-4.02$ SD height for age, and her increased height SD score (SDS) was 1.03. Her BA advanced from 2.5 to 5 years, as shown in Fig. 4. Her growth velocity increased by $7.6 \mathrm{~cm}$ in the first year and $7.0 \mathrm{~cm}$ in the second year. In the first year of treatment, her height improved to $93.4 \mathrm{~cm}(-4.59 \mathrm{SD}$ height for age), and her increased height SDS was 0.46 , as shown in Fig. 5. Because of the low IGF-1 level and decreased growth velocity, the dosage was increased from $0.2 \mathrm{mg} /$ $\mathrm{kg} / \mathrm{w}$ when she was 5 and $7 / 12$ years to $0.3 \mathrm{mg} / \mathrm{kg} / \mathrm{w}$ when she was 6 and $1 / 12$ years. In the second year, her height reached $100.4 \mathrm{~cm},-4.02 \mathrm{SD}$ height for age, and her increased height SDS was 0.57. Her biochemical parameters, blood glucose, and HbA1c were normal in the follow-up period. She had no manifestations of GH adverse effects. However, she had high IGF-1 and FT4 levels at a dose of $0.3 \mathrm{mg} / \mathrm{kg} /$ week. At 6 and $4 / 12$ years, she stopped GH treatment because of economic factors.

The fourth proband was a 12- and 9/12-year-old girl. She had short stature with brachydactyly, as shown in Fig. 6 . Her growth velocity was $2-3 \mathrm{~cm}$ per year. Her 


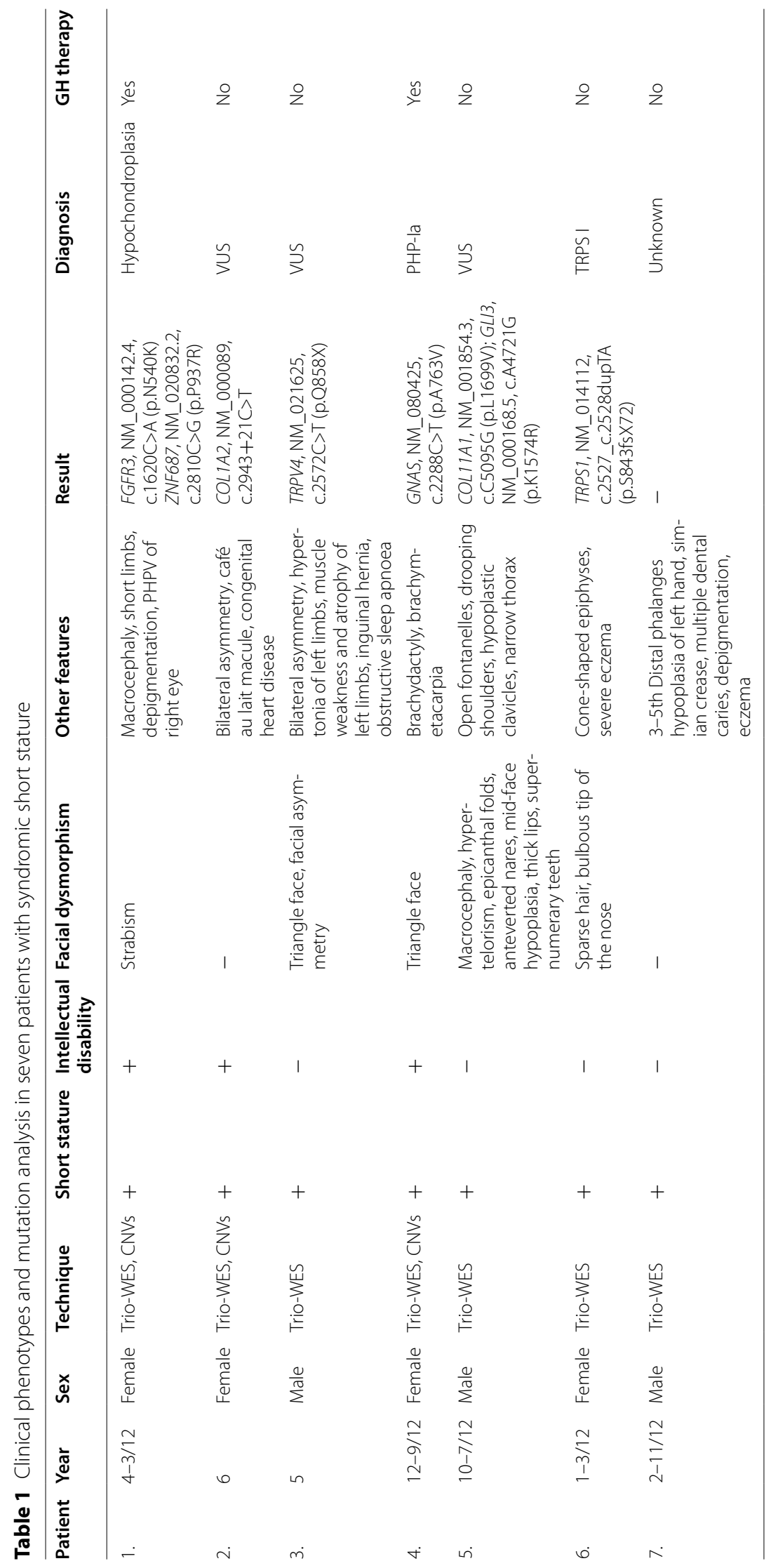



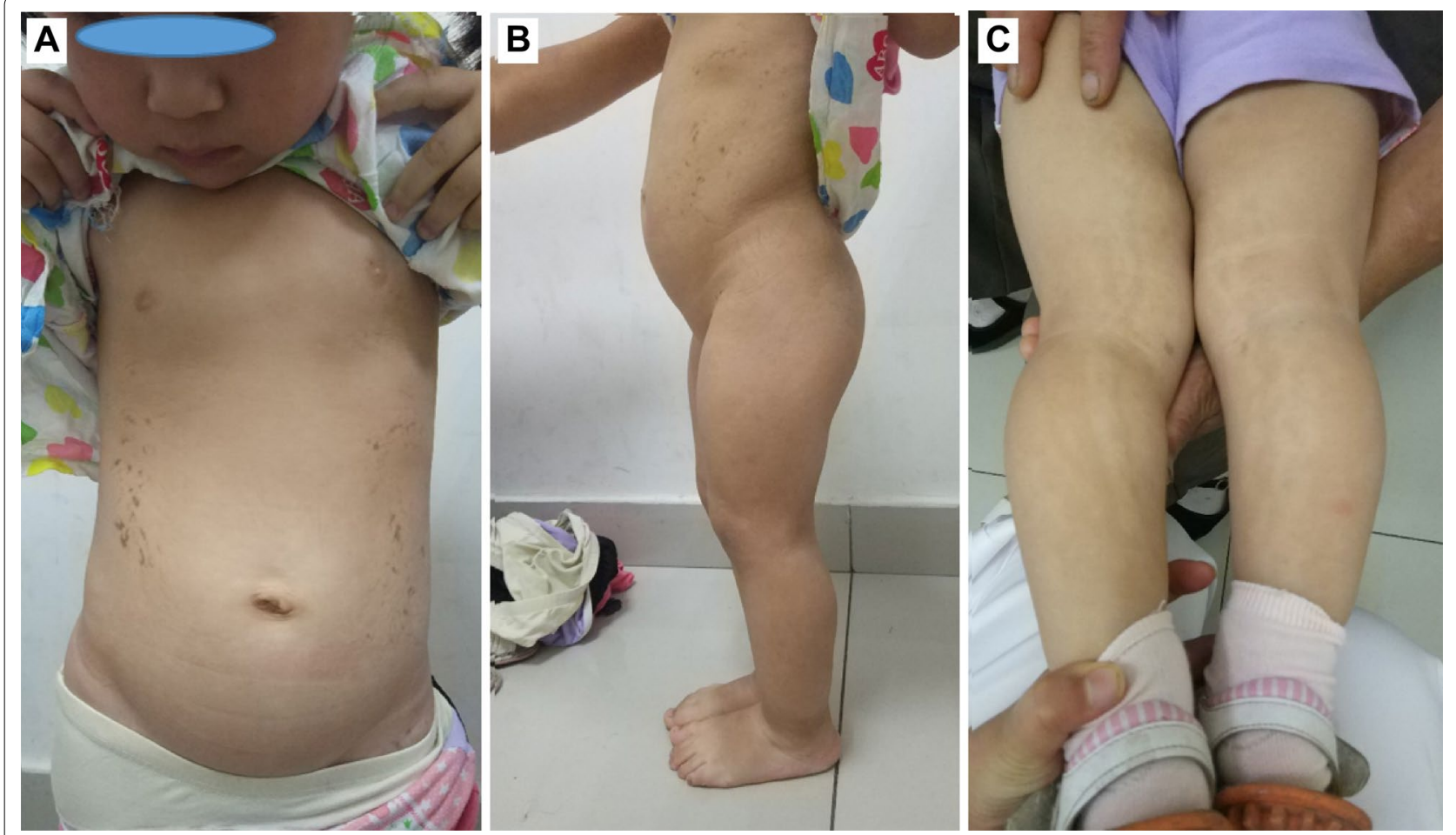

Fig. 1 Clinical features of the proband. A Brown spots on both sides of abdomen. B Lumbar lordosis with protruding abdomen. C Tibial bowing and linear depigmentation in both lower limbs
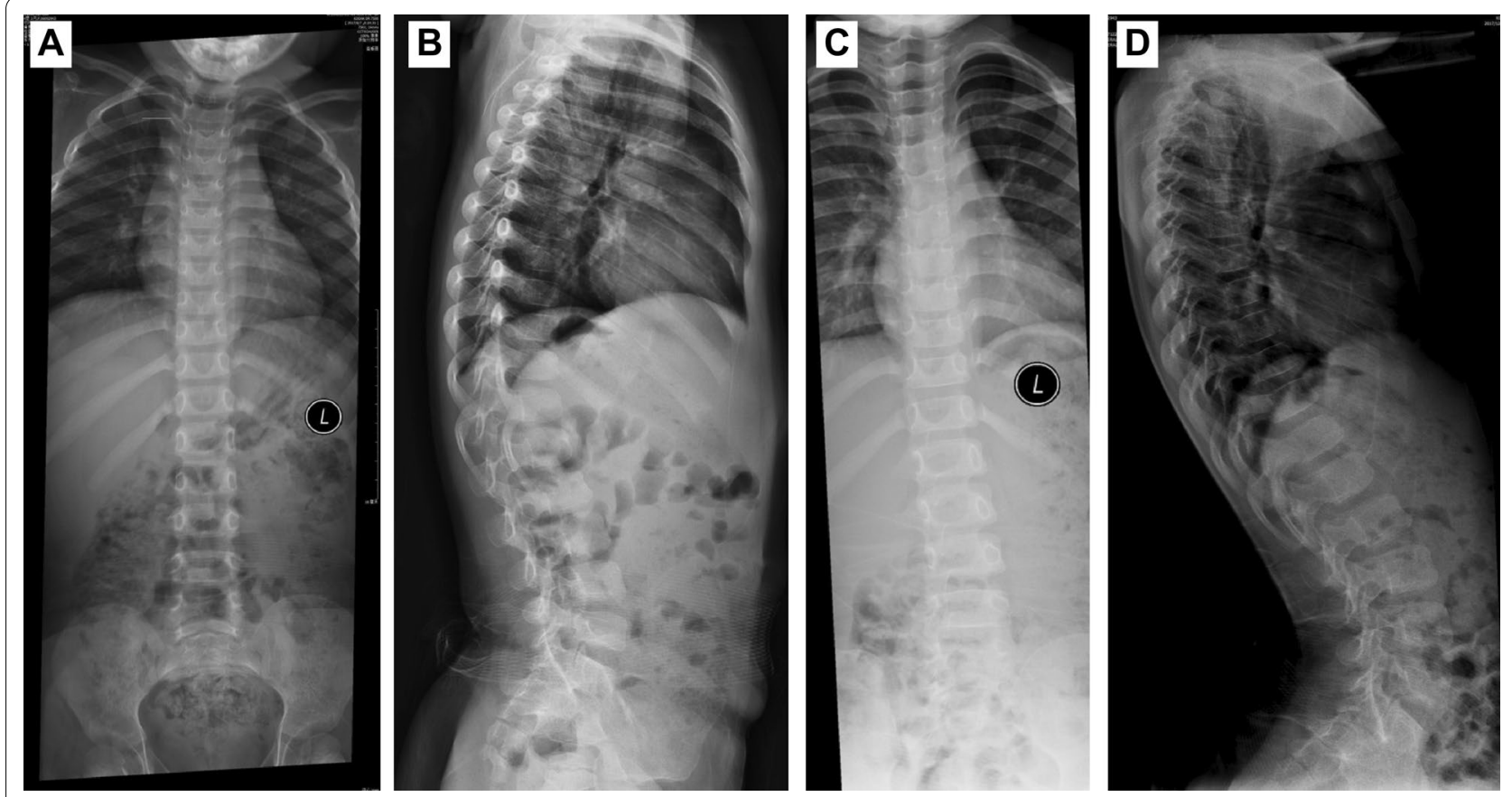

Fig. 2 Frontal and lateral spinal imaging data of the proband with hypochondroplasia. She had thoracic kyphosis and dorsal concavity of the lumbar vertebrate bodies. The interpedicular distance widened in the lower lumber spine more than in the upper lumber spine when she was $4-3 / 12$ years $(\mathbf{A}, \mathbf{B})$ and $4-9 / 12$ years $(\mathbf{C}, \mathbf{D})$ 

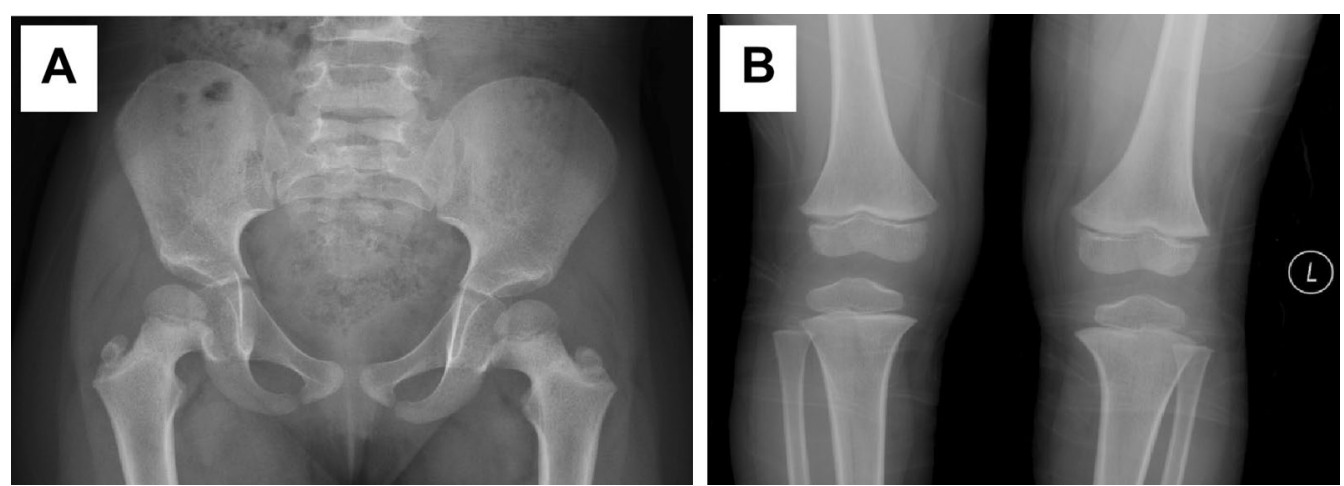

Fig. 3 A Short, broad femoral neck; short, squared ilea; and flattened acetabular roof (5 years). B Shortening of the long bones with metaphyseal flare (5-7/12 years)

height was $139.3 \mathrm{~cm}(-2.65 \mathrm{SD})$, her weight was $30.4 \mathrm{~kg}$ $(-2.26 \mathrm{SD})$, and her BMI was $15.67 \mathrm{~kg} / \mathrm{m}^{2}(-1.12 \mathrm{SD})$. Her pubertal stage was breast Tanner II and pubic hair Tanner I. She was born at full term by caesarean section. She had no history of perinatal asphyxia or difficulty feeding after birth. Her milestones were normal. She had mild intellectual disability and poor academic performance. She exhibited normal liver and kidney functions, myocardial enzymes and blood electrolytes. Indicators of bone metabolism were as follows: $\mathrm{Ca}$ 2.33 (2.25-2.67) $\mathrm{mmol} / \mathrm{L}, \mathrm{P} 1.59$ (1.45-2.10) $\mathrm{mmol} / \mathrm{L}$, ALP 256 (50-400) IU/L, and 25-hydroxy-vitamin $\mathrm{D}_{3}$ (25- $\left.(\mathrm{OH}) \mathrm{VD}_{3}\right) 22.42(30-100) \mathrm{ng} / \mathrm{mL}$. She had normal thyroid function at the first visit, as shown in Table 3. The GH concentration response to an exercise test was $23.10 \mathrm{ng} / \mathrm{mL}$. Her IGF-1 was 259 (143-693) ng/mL. Her BA was equivalent to approximately 13.5 years (Fig. 6B) at a $C A$ of 12 and $9 / 12$ years. Her pituitary magnetic resonance imaging (MRI) findings were normal. Her parents were nonconsanguineous. Her mother's height was $146.7 \mathrm{~cm}$, her weight was $51.5 \mathrm{~kg}$, and her BMI was $23.9 \mathrm{~kg} / \mathrm{m}^{2}$. Her mother had short stature, a round face, obesity, and a shortening of the 4th metatarsals (Fig. 6D). The mother refused to undergo a blood test, so her endocrine hormone levels were unknown. The father and older brother of the proband had normal phenotypes; their heights were $170 \mathrm{~cm}$ and $165 \mathrm{~cm}$, respectively.

Trio-WES identified the GNAS variant c. $2288 \mathrm{C}>\mathrm{T}$ p.A763V in the proband and her mother (Fig. 7). Bioinformatics analysis suggested that this variant was located in a highly conserved domain and was likely a pathogenic mutation. This mutation could cause GNAS inactivation. The paternal origin of the GNAS mutation in the mother was uncertain because of specimens from the proband's grandfather and grandmother were not available.
Substitutive short-acting rhGH treatment was started, as shown in Table 3. After 13 months, her height improved from $139.3 \mathrm{~cm}(-2.69 \mathrm{SD})$ to $145.0 \mathrm{~cm}(-2.36$ $\mathrm{SD})$, as shown in Fig. 8. Her growth velocity increased from $2-3$ to $4.75 \mathrm{~cm}$ /year. During treatment, she had elevated TSH levels, and subclinical hypothyroidism was diagnosed. Then, thyroxine $25 \mu$ g was administered daily. Her biochemical parameters, blood glucose, and HbA1c remained normal. She had no other adverse reactions. When she was 13 and 7/12 years, her BA was 14.5 years. Her intact parathyroid hormone (iPTH) level was 66.6 (15-65) $\mathrm{pg} / \mathrm{mL}$, while her $25-(\mathrm{OH}) \mathrm{VD}_{3}$ level was 32.88 (30-100) $\mathrm{ng} / \mathrm{mL}$. Indicators of bone metabolism were normal: Ca 2.38 (2.25-2.67) mmol/L, P 1.85 (1.45-2.10) $\mathrm{mmol} / \mathrm{L}$, and ALP 298 (50-400) IU/L. Her sex hormones were as follows: follicle-stimulating hormone (FSH) 9.00 IU/L, luteinizing hormone (LH) $2.03 \mathrm{IU} / \mathrm{L}$, prolactin (PRL) $126.26 \mathrm{mIU} / \mathrm{L}$, progesterone (P) $0.72 \mathrm{nmol} / \mathrm{L}$, oestradiol (E2) $277.0 \mathrm{pmol} / \mathrm{L}$, and testosterone (T) $2.36 \mathrm{nmol} / \mathrm{L}$. The patient stopped $\mathrm{rhGH}$ at the age of 13 and $11 / 12$ years. She had menarche at $14-3 / 12$ years.

The sixth proband was a 15 -month-old girl. Her clinical manifestations included short stature, sparse and fine hair, a bulbous nose tip, a long philtrum, a thin upper vermilion, a prominent forehead and cone-shaped phalangeal epiphyses (Fig. 9). Her height was $72.6 \mathrm{~cm}$ $(-2.27 \mathrm{SD})$, weight was $8.78 \mathrm{~kg}(-1.33 \mathrm{SD})$, and BMI was $16.66 \mathrm{~kg} / \mathrm{m}^{2}(0.31 \mathrm{SD})$. The patient was born at full term by caesarean section. Her birth weight was $2480 \mathrm{~g}$ $(-2.19 \mathrm{SD})$, and her birth length was $46(-2.22 \mathrm{SD}) \mathrm{cm}$. She was followed up in our clinical department. When she was 2 and $1 / 12$ years, her height was $81.6 \mathrm{~cm}(-1.94$ $\mathrm{SD})$, weight was $10.3 \mathrm{~kg}(-1.56 \mathrm{SD})$, BMI was $15.7 \mathrm{~kg} /$ $\mathrm{m}^{2}(-0.14 \mathrm{SD})$, and head circumference was $48 \mathrm{~cm}(0.41$ SD). Her IGF-1 was $73.5(51-303) \mathrm{ng} / \mathrm{mL}$. She had normal thyroid function. 


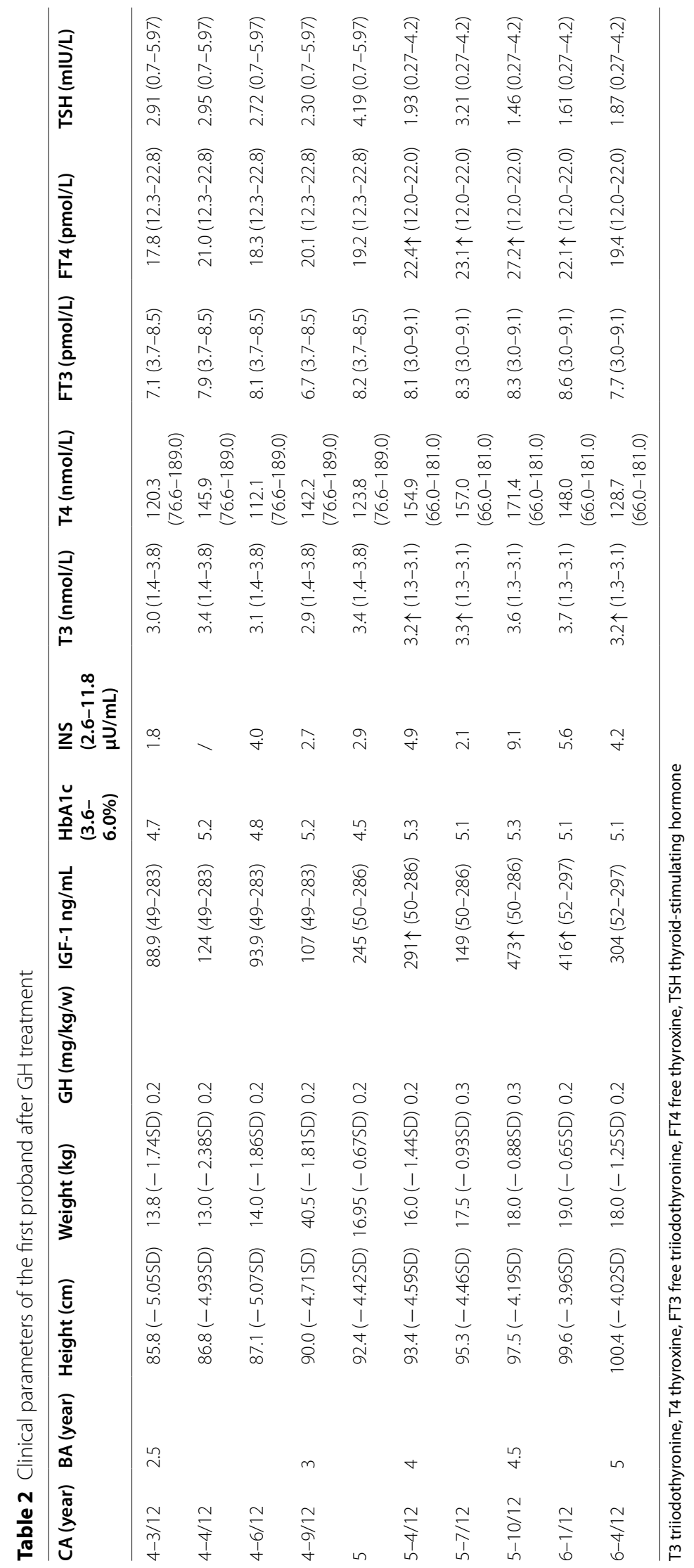




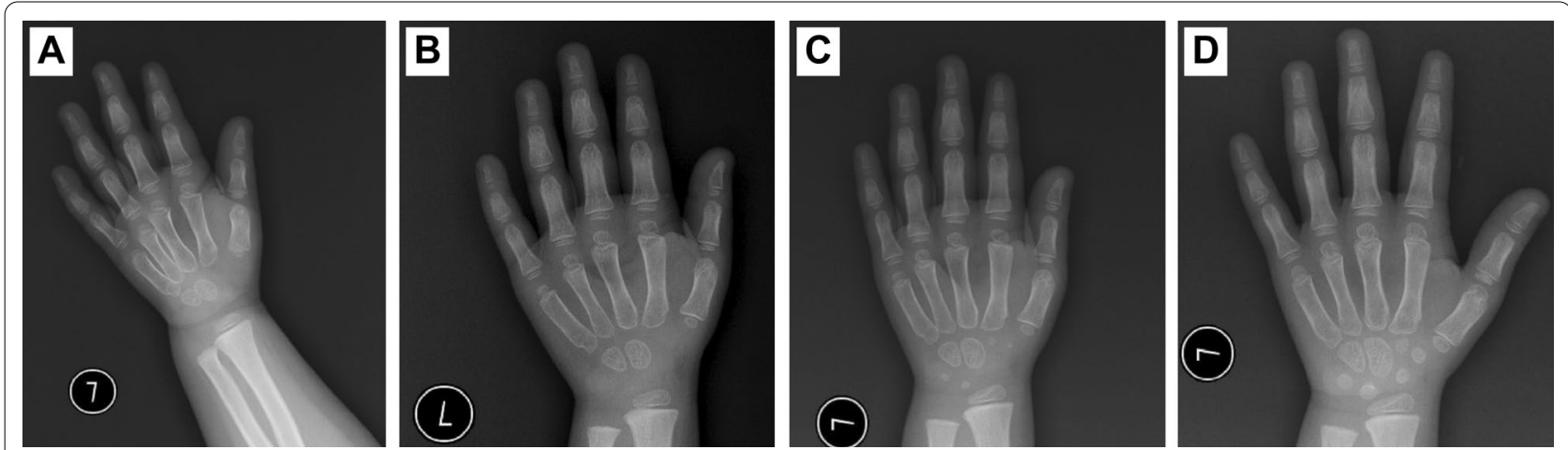

Fig. 4 Bone age radiograph in the course of GH treatment. A CA: 4-3/12 years; BA: 2.5 years. B CA: 4-9/12 years; BA: 3 years. C CA: 5-4/12 years; BA: 4 years. D CA: 6-4/12 years; BA: 5 years

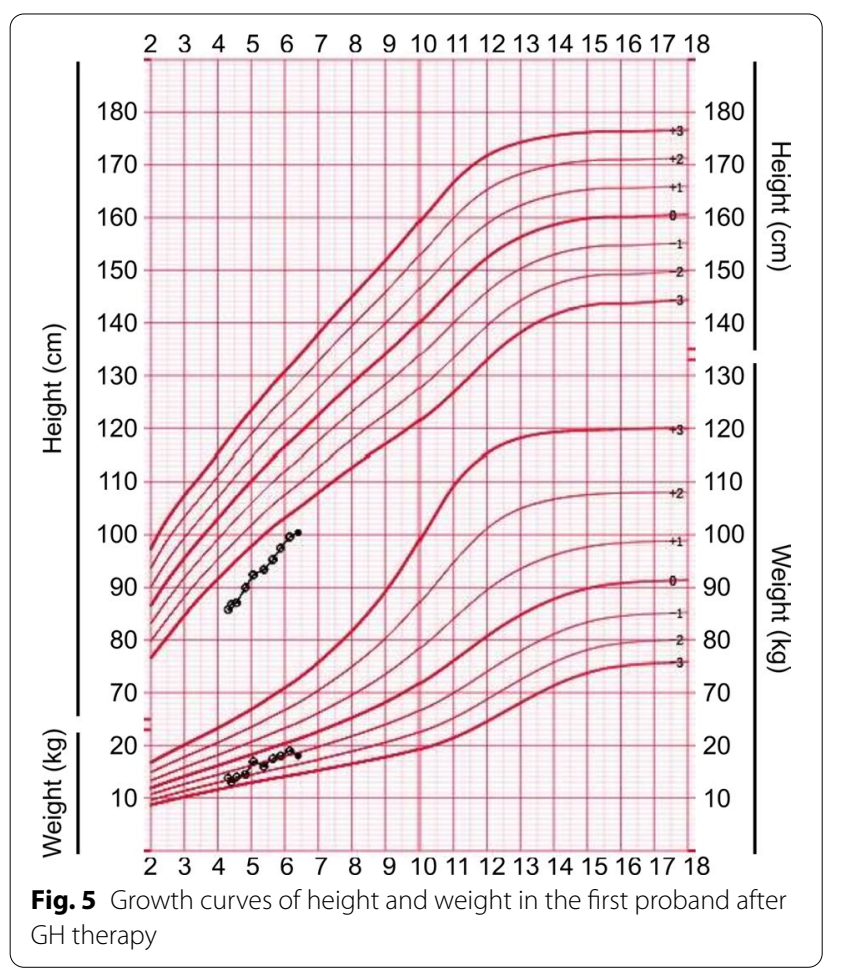

There were five affected patients in three generations in an autosomal-dominant manner, as shown in Fig. 9. The proband's father and older sister had similar manifestations: sparse hair, a bulbous nose tip, a long philtrum, a thin upper vermilion, and cone-shaped phalangeal epiphyses. In addition to these specific features, her father also had overcrowded teeth. The height of the affected father (II-1) and uncle (II-4) was approximately $160 \mathrm{~cm}$. The proband's grandmother (I-2) was approximately $150 \mathrm{~cm}$ in height. The proband's older sister was 10 and $7 / 12$ years old at presentation. She had been diagnosed with central precocious puberty $(\mathrm{CPP})$ and received leuprorelin (gonadotropin releasing hormone agonist, GNRHa) therapy for 28 months since the age of 8 and $3 / 12$ years in another hospital. Her height was $145.6 \mathrm{~cm}$ (0.19 SD), and her weight was $34.3 \mathrm{~kg}(-0.03 \mathrm{SD})$. She was born at full term by caesarean section. Her birth weight was $2750 \mathrm{~g}(-1.30 \mathrm{SD})$, and her birth length was $48 \mathrm{~cm}(-1.01 \mathrm{SD})$. When she was 10 and $11 / 12$ years old and her BA was almost 11 years (Fig. 9D), leuprorelin was withdrawn. At 11 and 3/12 years old, her sex hormones were normal: FSH 6.64 IU/L, LH $3.80 \mathrm{IU} / \mathrm{L}, \mathrm{PRL}$ $226.62 \mathrm{mIU} / \mathrm{L}, \mathrm{P} 0.51 \mathrm{nmol} / \mathrm{L}$, E2 $186 \mathrm{pmol} / \mathrm{L}$, and T $1.70 \mathrm{nmol} / \mathrm{L}$. The serum IGF-1 was $390(111-551) \mathrm{ng} /$ $\mathrm{mL}$. When she was 14 and 4/12 years old, her near-adult height reached $160 \mathrm{~cm}(0.19$ SD). Her mother's height was $140 \mathrm{~cm}$, which was caused by scoliosis after a traffic accident. A TRPS1 mutation (c.2526_c.2527dupTA (p. S843fsX72) in exon 5 was detected in the affected patients of the pedigree (Fig. 9).

The third proband had short stature, bilateral asymmetry, muscle atrophy of the left limbs, and an inguinal hernia. One novel TRPV4 mutation (c.2572C $>\mathrm{T}$ p.Q858X) was identified in the patient and her unaffected father; however, the phenotype-genotype correlation was uncertain [19-21]. One novel COL11A1 variation (c.C5095G p. L1699V) and one novel GLI3 variation (c.A4721G p.K1574R) was identified in the fifth proband with cranial dysplasia, clavicle hypoplasia and supernumerary teeth, which were the main features of cleidocranial dysplasia [22, 23]. Both were variants of uncertain significance (VUSs) (http://wintervar.wglab.org/ and http://varcards.biols.ac.cn/).

\section{Discussion}

We performed Trio-WES analysis in seven patients with syndromic short stature of unknown aetiology and TrioWES and CNV combined analysis in three patients with concurrent intellectual disability. One FGFR3 mutation 

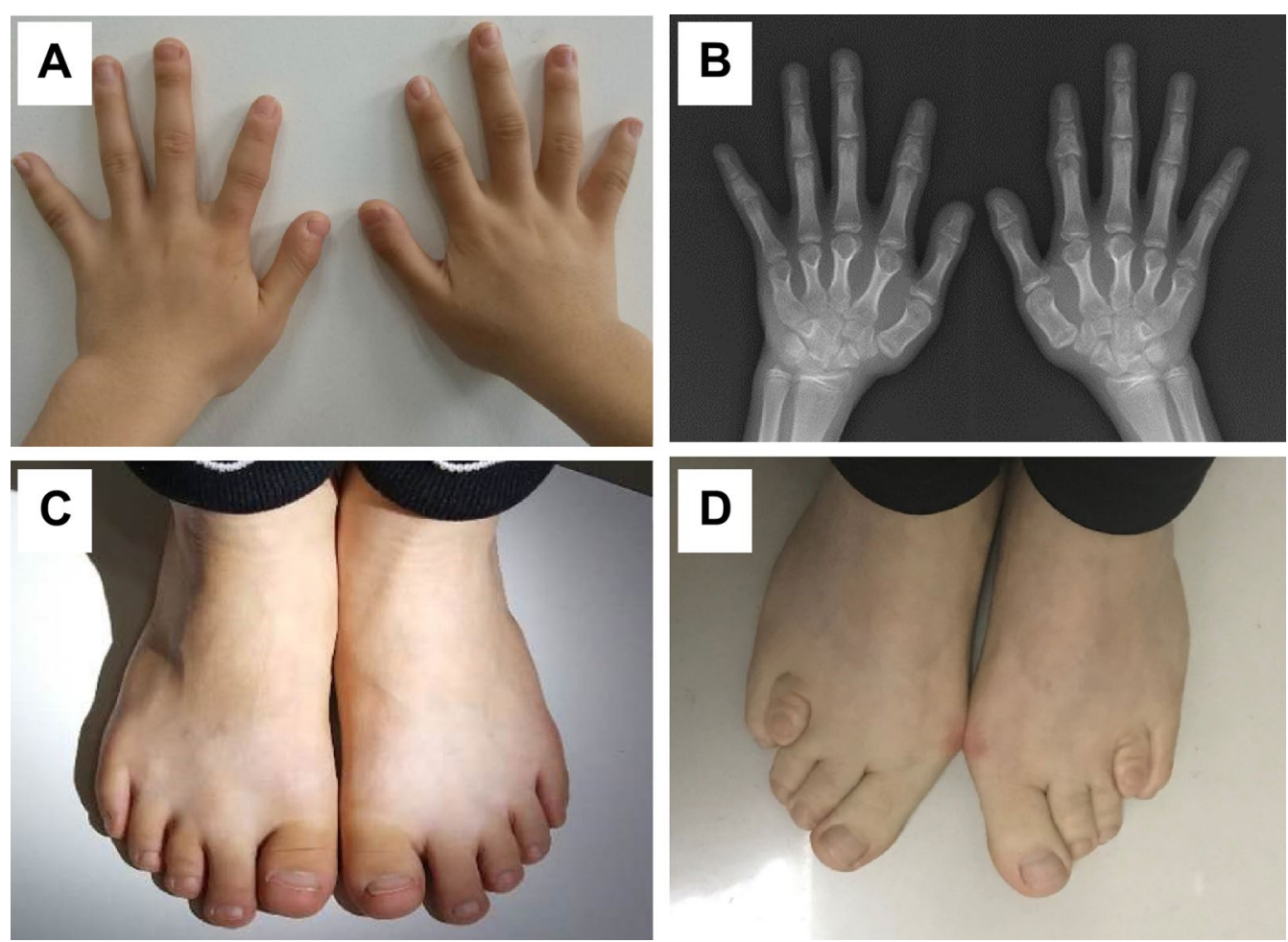

Fig. 6 Clinical features and radiological manifestations of the fourth pedigree. A, B The proband had a shortening of the metacarpals, distal phalanx of the thumb and middle figure, middle phalanx of the index figure and the fifth finger. CThe proband had short feet and brachydactyly. D Her mother had a shortening of the 4th metatarsals

(c.1620C>A p.N540K), one likely pathogenic GNAS mutation (c.2288C $>$ T p.A763V), and one TRPS1 mutation (c.2527_c.2528dupTA p.S843fsX72) was identified in three pedigrees with hypochondroplasia, pseudohypoparathyroidism Ia (PHP-Ia), and trichorhinophalangeal syndrome type I (TRPS I). Our findings emphasize the importance of Trio-WES analysis in identifying the aetiology of syndromic short stature.

\section{Hypochondroplasia}

FGFR3, located at 4p16.3, is a receptor tyrosine kinase and a member of the fibroblast growth factor receptor family with a highly conserved structure. FGFR genes are characterized by an extracellular ligand-binding domain consisting of three immunoglobulin (Ig) subdomains, a transmembrane domain, and a split intracellular tyrosine kinase domain [24]. FGFR3 mutations have been reported to cause various types of skeletal dysplasia, especially achondroplasia and hypochondroplasia, in an autosomal-dominant manner [25]. The most common and specific FGFR3 mutation in achondroplasia is c.1138G $>$ A or c.1620G $>$ C (p.G380R) and in hypochondroplasia is c. $1620 \mathrm{C}>\mathrm{A}$ or c. $1620 \mathrm{C}>\mathrm{G}$ (p.N540K) $[16,26]$. Hypochondroplasia has many features that are similar to achondroplasia, but hypochondroplasia is milder. The effects of FGFR3 mutation have been shown to result in constitutive activation of receptor tyrosine kinase and negative regulation of cartilage growth [16].

Hypochondroplasia is a genetic skeletal dysplasia characterized by disproportionate short stature, lumbar lordosis, stocky build, short arms and legs, and macrocephaly $[16,27]$. The diagnosis of hypochondroplasia is based on clinical manifestations, radiological features and FGFR3 mutation analysis. The proband had short stature, macrocephaly, body disproportion, lumbar lordosis, and joint laxity. However, the coexistence of intellectual disability and PHPV made the diagnosis complicated. An FGFR3 mutation c.1620C $>$ A (p.N540K) was identified in the proband and her father. Both of them had intellectual disability, which is more frequent in hypochondroplasia than in achondroplasia $[16,28]$. In addition, unlike achondroplasia, the proband and her affected father had normal faces and lacked trident hands. They were diagnosed as having hypochondroplasia. The PHPV in the proband may be caused by other unidentified gene mutations.

As the proband had concurrent partial GH deficiency, she had severe short stature. Similar to other studies, 


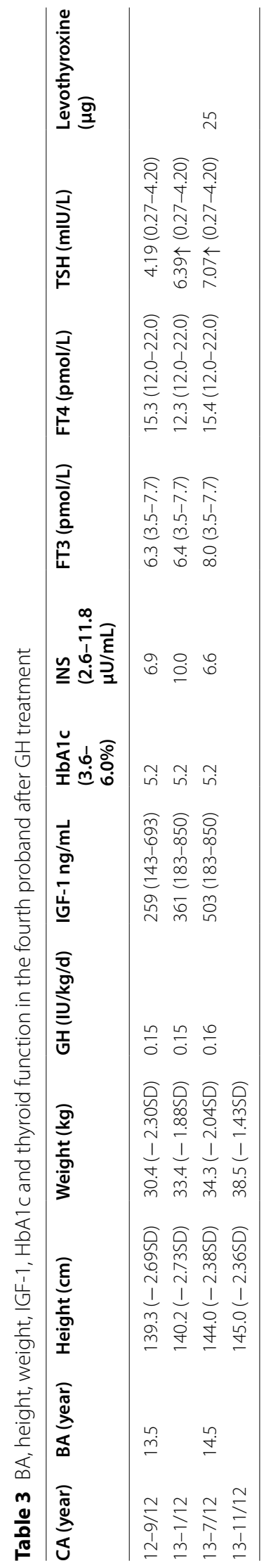



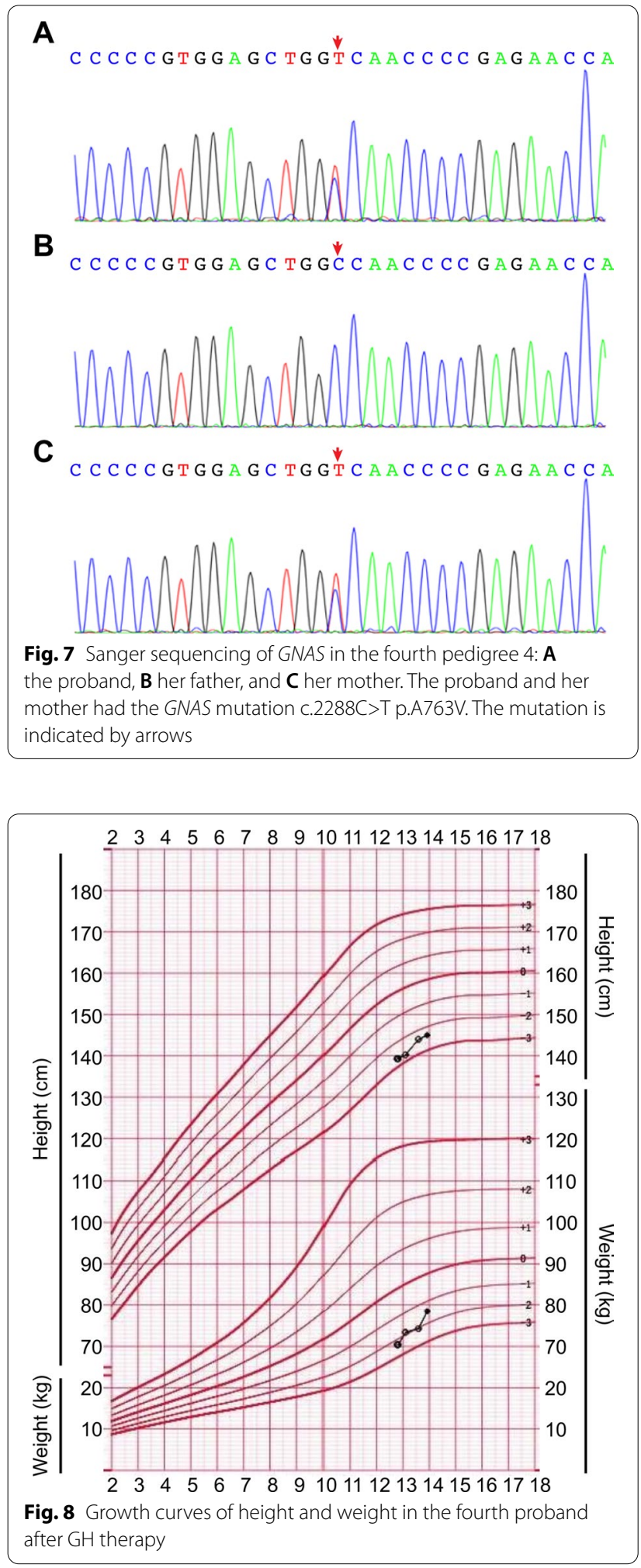

the proband had a good response to GH therapy [27]. GH improved her height from $85.8 \mathrm{~cm}(-5.05 \mathrm{SD})$ to $100.4 \mathrm{~cm}(-4.02 \mathrm{SD})$, and her increased height SDS was
1.03 after 25 months of treatment. Her growth velocity and IGF-1 level decreased in the second year; however, an increase in $\mathrm{GH}$ could maintain her growth velocity. GH therapy should be considered to increase the final adult height in patients with this growth disorders [18, 29]. Data about final height in the proband should be followed up.

\section{PHP}

GNAS encodes the alpha subunit of the stimulatory guanine nucleotide-binding protein, which is downstream of many different $\mathrm{G}$ protein-coupled hormone receptors [30]. Disorders of GNAS inactivation include various phenotypes, including PHP Ia, Ib, and Ic; pseudoPHP (PPHP); progressive osseous heteroplasia $(\mathrm{POH})$, and osteoma cutis (OC) [31]. The specific phenotype was determined by the mutation type and parental origin of the affected allele [32]. PHP-Ia is caused by maternal heterozygous GNAS mutations and characterized by multiple hormonal resistance and characteristic features of Albright's hereditary osteodystrophy (AHO) [32].

The proband and her mother had short stature and brachydactyly. Both the proband and her mother were positive for the GNAS likely pathogenic mutation c.2288C $>$ T p.A763V. GNAS, located at the GNAS complex locus at $20 \mathrm{q} 13.32$, is encoded by exons $1-13$. GNAS mutation c. $2288 \mathrm{C}>\mathrm{T}$ p.A763V, located in exon 5 , could affect the structure and function of GNAS and neuroendocrine secretory protein 55 (NESP55) in tissues with maternal-specific expression, such as the renal proximal tubules, thyroid, gonads, and pituitary [30]. This heterozygous mutation can also cause haploinsufficiency in biallelically expressed tissues such as bone and growth plate chondrocytes [30].

The diagnosis of PHP was based on clinical manifestations, endocrine hormone levels and GNAS gene testing. The proband had short stature, brachydactyly, multiple hormone resistance, and mild intellectual disability. She was characterized by PTH resistance and TSH resistance. PTH was inappropriately elevated considering normal calcium and phosphate levels, which indicates the peripheral resistance of PTH. She had TSH resistance with high TSH levels and normal thyroid hormone levels. Her mother's manifestations were consistent with AHO: short stature, a round face, and brachydactyly type E (shortening mainly of the 4th metatarsals). The proband and her mother show obvious phenotypic heterogeneity.

Because of the low normal IGF-1 level, especially the lack of a pubertal growth spurt, linear growth attenuation in the proband worsened after 10 years. Her height SDS increased from -2.69 to -2.36 after 13 months of GH therapy. During GH treatment, she had a high TSH level, and levothyroxine was administered. There were 


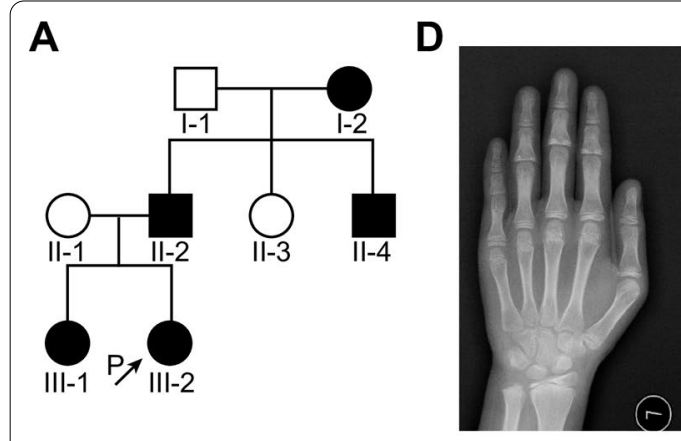

E

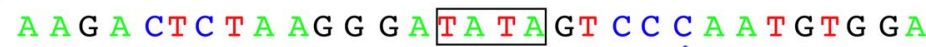

B
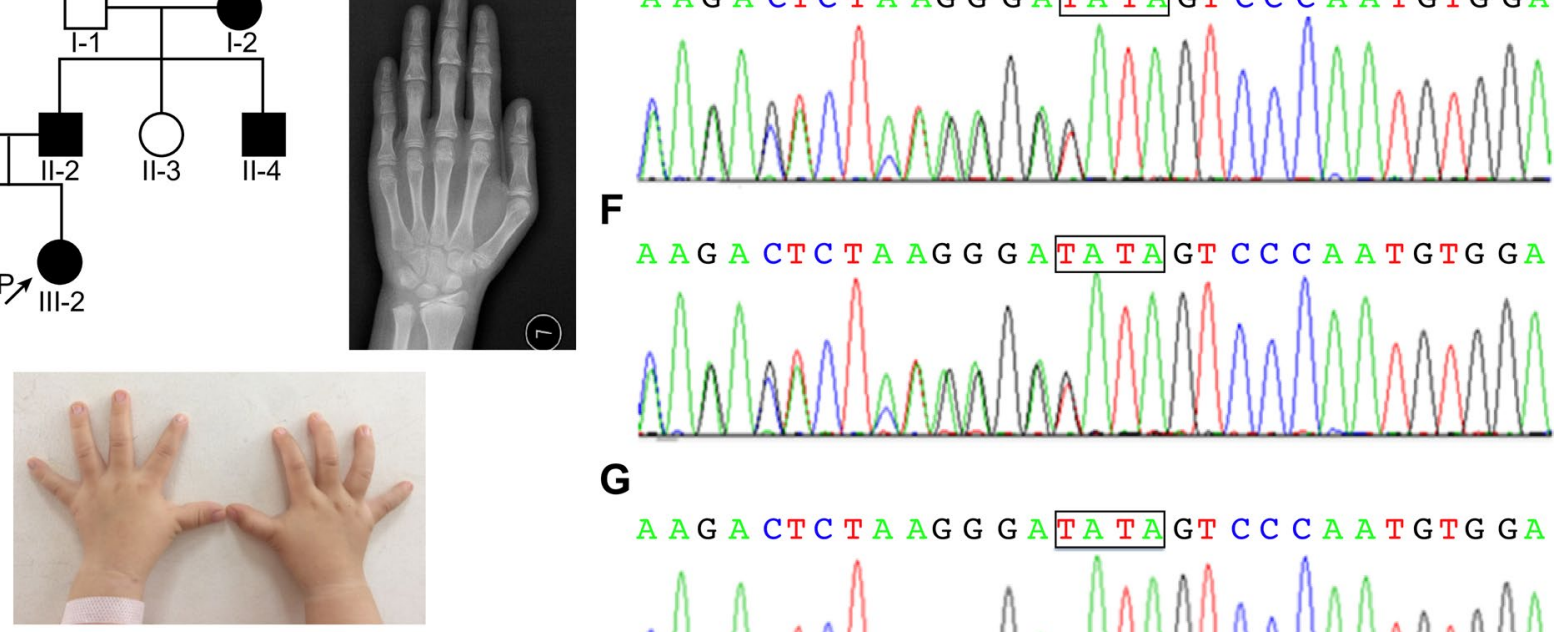

$\mathbf{F}$ A A

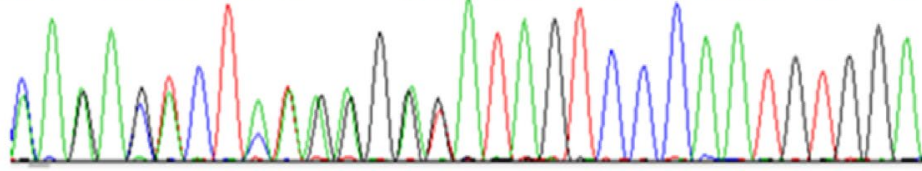

G А А

C
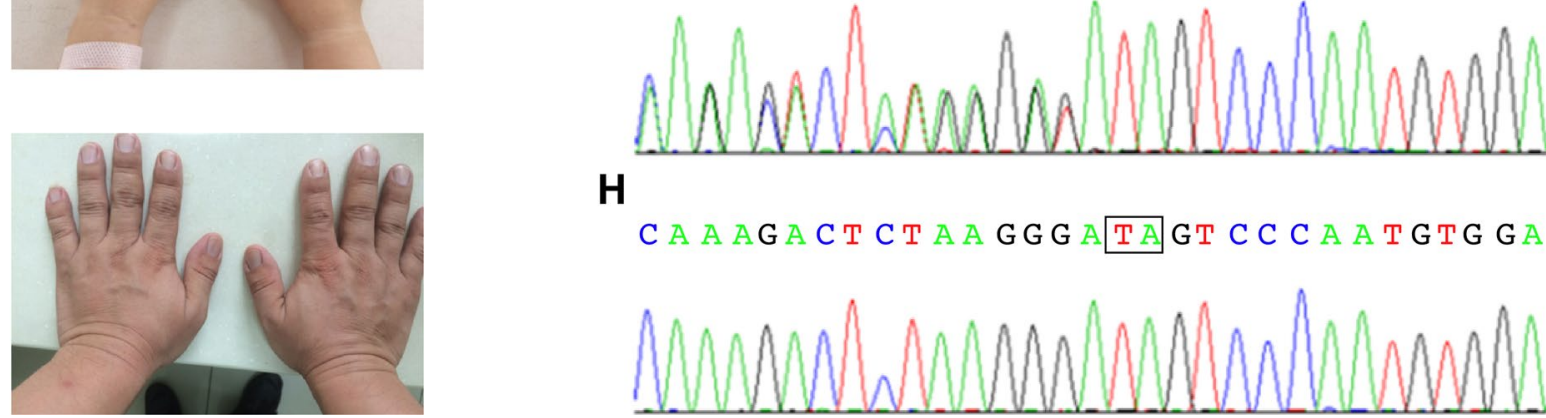

H

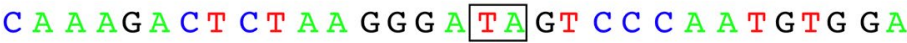

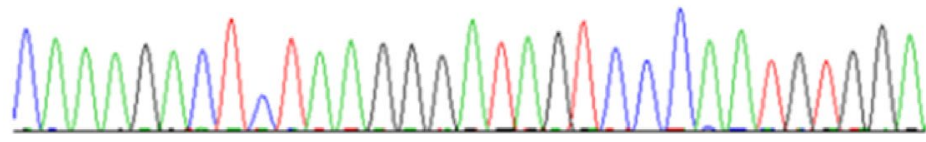

Fig. 9 Clinical manifestations of the sixth pedigree. A Pedigree tree of the family with TRPS I. The proband (B) and her father (C) had short and stubby hands. D Bone age radiograph of the patient's older sister showed the cone-shaped epiphyses with a shortening of the middle phalanxes of the second to fifth fingers. The TRPS1 mutation c.2526_c.2527dupTA (p. S843fsX72) was detected in the three affected patients: $\mathbf{E}$ the proband, $\mathbf{F}$ her older sister, $\mathbf{G}$ her father, and $\mathbf{H}$ her mother

no other side effects, indicating that GH was effective and safe for this PHP-Ia patient. The observations in this proband were consistent with a previous study showing that GH therapy had positive effects on prepubertal children with PHP-Ia [33]. The height changes, benefits, and side effects during GH treatment need to be monitored in a large sample of individuals with this rare disease.

\section{TRPS I}

TRPS I is characterized by craniofacial and skeletal malformations, including short stature, sparse hair, a bulbous nose, a long flat philtrum, a thin upper vermilion border, protruding ears, cone-shaped phalanges and hip dysplasia [34]. The disorder is caused by TRPS1 haploinsufficiency. TRPS1 is located at 8q23.3 and encodes a zinc-finger transcription repressor involved in the regulation of chondrocyte and perichondrium development [35]. We report here a family with a novel TRPS1 mutation c.2526_c.2527dupTA (p.S843fsX72). The father and his two daughters carried this mutation and had clinical manifestations of TRPS I.
The insertion frameshift mutation c.2526_c.2527dupTA (p. S843fsX72) in TRPS1, which leads to the absence of the GATA DNA-binding zinc finger, potential nuclear localization signals and IKAROS-like zinc-finger motif, was predicted to result in a loss of function in transcription [36, 37]. The affected patient in our study had mild short stature and brachydactyly, consistent with other studies showing that most patients with TRPS1 nonsense mutations have a less severe phenotype [37, 38].

The GH response in patients with TRPS I has been inconsistent according to previous studies [34]. The proband and her older sister had clinical manifestations of TRPS I and normal IGF-1 levels. The proband had short stature. Because of her young age, the proband's parents refused GH treatment. Her older sister had CPP and received 32 months of GNRHa therapy. At the last follow-up, she had reached a normal near-adult height. The older sister's final height improved to normal levels after GNRHa treatment, which can postpone premature closure of the growth plates [37]. GNRHa therapy for TRPS I patients with CPP has not been reported previously. 


\section{Conclusions}

Individuals with syndromic short stature show genetic and phenotypic heterogeneity, making it difficult to obtain a definite diagnosis. This study emphasizes the importance of Trio-WES in patients with syndromic short stature suspected of having a genetic disorder. A definitive molecular diagnosis provides an important basis for prognosis prediction, therapy guidance and genetic counselling. Our study demonstrated that short-term GH treatment had positive effects on hypochondroplasia and PHP-Ia. We advocate studies with larger samples to obtain more evidence of the efficacy of $\mathrm{GH}$ treatment in patients with syndromic short stature.

\begin{abstract}
Abbreviations
CNV: Copy number variant; rhGH: Recombinant human growth hormone; Trio-WES: Trio-whole-exome sequencing; SD: Standard deviation; SNPs: Single nucleotide polymorphisms; MAF: Minor allele frequency; ACMG: American College of Medical Genetics; OMIM: Online Mendelian Inheritance in Man; HGMD: Human Gene Mutation Database; DGV: Database of Genomic Variants; HbA1C: Haemoglobin A1c; INS: Insulin; IGF-1: Insulin-like growth factor-1; PHPV: Persistent hyperplasia of primary vitreous; FGFR3: Fibroblast growth factor receptor 3; CA: Chronological age; BA: Bone age; T3: Triiodothyronine; T4: Thyroxine; FT3: Free triiodothyronine; FT4: Free thyroxine; TSH: Thyroid-stimulating hormone; PH: Pubic hair; iPTH: Parathyroid hormone; FSH: Follicle-stimulating hormone; LH: Luteinizing hormone; PRL: Prolactin; P: Progesterone; E2: Oestradiol; T: Testosterone; CPP: Central precocious puberty; GNRHa: Gonadotropin releasing hormone agonist; VUS: Variant of uncertain significance; PHPla, Ib, Ic: Pseudohypoparathyroidism la, Ib, and Ic; TRPS I: Trichorhinophalangeal syndrome type I; PPHP: Pseudopseudohypoparathyroidism; $\mathrm{POH}$ : Progressive osseous heteroplasia; OC: Osteoma cutis; AHO: Albright's hereditary osteodystrophy; NESP55: Neuroendocrine secretory protein 55.
\end{abstract}

\section{Acknowledgements}

We would like to thank all members of the families participating in the study for agreeing to the publication of their available clinical data in medical journals.

\section{Authors' contributions}

NW interpreted the patient data. HS wrote the manuscript. NL analysed the radiological examinations of these patients. All authors read and approved the final manuscript.

\section{Funding}

This study was supported by research grants from the Beijing Jishuitan Hospital Nova Program (XKXX201608). HS designed the study. NW collected clinical data of patients.

\section{Availability of data and materials}

The datasets generated or analysed during this study are available in the Mendeley repository, https://data.mendeley.com/datasets/3dytgcwgk7/1.

\section{Declarations}

\section{Ethics approval and consent to participate}

The study was approved by the Ethics Committee of Beijing Jishuitan Hospital. Written informed consent was obtained from the participants and parents of the patients in the study.

\section{Consent for publication}

Written informed consent to publish the clinical details and images was obtained from the participants and parents of the patients in the study.

\section{Competing interests}

The authors declare that they have no competing interests.

\section{Author details}

${ }^{1}$ Department of Paediatrics, Beijing Jishuitan Hospital, No. 31 of Xinjiekou Dongjie Street, Xi Cheng District, Beijing 100035, People's Republic of China. ${ }^{2}$ Department of Radiology, Beijing Jishuitan Hospital, No. 31 of Xinjiekou Dongjie Street, Xi Cheng District, Beijing 100035, People's Republic of China.

Received: 15 July 2021 Accepted: 28 October 2021

Published online: 05 November 2021

\section{References}

1. Homma TK, Krepischi ACV, Furuya TK, Honjo RS, Malaquias AC, Bertola DR, et al. Recurrent copy number variants associated with syndromic short stature of unknown cause. Horm Res Paediatr. 2018;89:13-21.

2. Homma TK, Freire BL, Honjo Kawahira RS, Dauber A, Funari MFA, Lerario $\mathrm{AM}$, et al. Genetic disorders in prenatal onset syndromic short stature identified by exome sequencing. J Pediatr. 2019;215:192-8.

3. Jee $\mathrm{YH}$, Baron J, Nilsson O. New developments in the genetic diagnosis of short stature. Curr Opin Pediatr. 2018;30:541-7.

4. Gravholt $\mathrm{CH}$, Viuff MH, Brun S, Stochholm K, Andersen NH. Turner syndrome: mechanisms and management. Nat Rev Endocrinol. 2019:15:601-14.

5. Butler MG, Miller JL, Forster JL. Prader-Willi syndrome-clinical genetics, diagnosis and treatment approaches: an update. Curr Pediatr Rev. 2019;15:207-44.

6. Noonan JA, Kappelgaard AM. The efficacy and safety of growth hormone therapy in children with noonan syndrome: a review of the evidence. Horm Res Paediatr. 2015;83:157-66.

7. Huang Z, Sun Y, Fan Y, Wang L, Liu H, Gong Z, et al. Genetic evaluation of 114 Chinese short stature children in the next generation era: a single center study. Cell Physiol Biochem. 2018:49:295-305.

8. Miller DT, Adam MP, Aradhya S, Biesecker LG, Brothman AR, Carter NP, et al. Consensus statement: chromosomal microarray is a first-tier clinical diagnostic test for individuals with developmental disabilities or congenital anomalies. Am J Hum Genet. 2010;86:749-64.

9. Wang J, Wang $Y$, Wang $L$, Chen WY, Sheng $M$. The diagnostic yield of intellectual disability: combined whole genome low-coverage sequencing and medical exome sequencing. BMC Med Genomics. 2020;13:70.

10. Grunauer M, Jorge AAL. Genetic short stature. Growth Horm IGF Res. 2018:38:29-33.

11. Siklar Z, Berberoglu M. Syndromic disorders with short stature. J Clin Res Pediatr Endocrinol. 2014;6:1-8.

12. Collett-Solberg PF, Jorge AAL, Boguszewski MCS, Miller BS, Choong CSY, Cohen P, et al. Growth hormone therapy in children; research and practice-a review. Growth Horm IGF Res. 2019;44:20-32.

13. Richards S, Aziz N, Bale S, Bick D, Das S, Gastier-Foster J, et al. Standards and guidelines for the interpretation of sequence variants: a joint consensus recommendation of the American College of Medical Genetics and Genomics and the Association for Molecular Pathology. Genet Med. 2015;17:405-24.

14. Kearney HM, Thorland EC, Brown KK, Quintero-Rivera F, South ST, Working Group of the American College of Medical Genetics Laboratory Quality Assurance Committee. American College of Medical Genetics standards and guidelines for interpretation and reporting of postnatal constitutional copy number variants. Genet Med. 2011;13:680-5.

15. Cooley LD, Lebo M, Li MM, Slovak ML, Wolff DJ, Working Group of the American College of Medical Genetics, et al. American College of Medical Genetics and Genomics technical standards and guidelines: microarray analysis for chromosome abnormalities in neoplastic disorders. Genet Med. 2013;15:484-94.

16. Bober MB, Bellus GA, Nikkel SM, Tiller GE. Hypochondroplasia. In: Adam MP, Ardinger HH, Pagon RA, Wallace SE, Bean LJH, Mirzaa G, Amemiya A, editors. GeneReviews((R)). Seattle: University of Washington; 1993.

17. Hasegawa K, Tanaka H. Children with short-limbed short stature in pediatric endocrinological services in Japan. Pediatr Int. 2014;56:809-12. 
18. Arenas MA, Del Pino M, Fano V. FGFR3-related hypochondroplasia: Iongitudinal growth in 57 children with the p.Asn540Lys mutation. J Pediatr Endocrinol Metab. 2018;31:1279-84.

19. Verma P, Kumar A, Goswami C. TRPV4-mediated channelopathies. Channels (Austin). 2010:4:319-28

20. Evangelista T, Bansagi B, Pyle A, Griffin H, Douroudis K, Polvikoski T, et al. Phenotypic variability of TRPV4 related neuropathies. Neuromuscul Disord. 2015;25:516-21.

21. Echaniz-Laguna A, Dubourg O, Carlier P, Carlier RY, Sabouraud P, Pereon Y, et al. Phenotypic spectrum and incidence of TRPV4 mutations in patients with inherited axonal neuropathy. Neurology. 2014;82:1919-26.

22. Xu W, Chen Q, Liu C, Chen J, Xiong F, Wu B. A novel, complex RUNX2 gene mutation causes cleidocranial dysplasia. BMC Med Genet. 2017;18:13.

23. Zhang X, Liu Y, Wang X, Sun X, Zhang C, Zheng S. Analysis of novel RUNX2 mutations in Chinese patients with cleidocranial dysplasia. PLoS ONE. 2017;12:e0181653.

24. Johnson DE, Williams LT. Structural and functional diversity in the FGF receptor multigene family. Adv Cancer Res. 1993;60:1-41.

25. Ornitz DM, Legeai-Mallet L. Achondroplasia: development, pathogenesis, and therapy. Dev Dyn. 2017:246:291-309.

26. Pauli RM. Achondroplasia: a comprehensive clinical review. Orphanet J Rare Dis. 2019;14:1.

27. Cetin T, Siklar Z, Kocaay P, Berberoglu M. Evaluation of efficacy of longterm growth hormone therapy in patients with hypochondroplasia. J Clin Res Pediatr Endocrinol. 2018;10:373-6.

28. Linnankivi T, Makitie O, Valanne L, Toiviainen-Salo S. Neuroimaging and neurological findings in patients with hypochondroplasia and FGFR3 N540K mutation. Am J Med Genet A. 2012;158A:3119-25.

29. Ramaswami U, Hindmarsh PC, Brook CG. Growth hormone therapy in hypochondroplasia. Acta Paediatr Suppl. 1999;88:116-7.

30. Turan S, Bastepe M. GNAS spectrum of disorders. Curr Osteoporos Rep. 2015;13:146-58

31. Haldeman-Englert CR, Hurst ACE, Levine MA. Disorders of GNAS inactivation. In: Adam MP, Ardinger HH, Pagon RA, Wallace SE, Bean LJH, Stephens
K, Amemiya A, editors. GeneReviews((R)). Seattle: University of Washington; 1993.

32. Bastepe M, Juppner H. GNAS locus and pseudohypoparathyroidism. Horm Res. 2005;63:65-74.

33. Mantovani G, Ferrante E, Giavoli C, Linglart A, Cappa M, Cisternino M, et al. Recombinant human $\mathrm{GH}$ replacement therapy in children with pseudohypoparathyroidism type la: first study on the effect on growth. J Clin Endocrinol Metab. 2010;95:5011-7.

34. Merjaneh L, Parks JS, Muir AB, Fadoju D. A novel TRPS1 gene mutation causing trichorhinophalangeal syndrome with growth hormone responsive short stature: a case report and review of the literature. Int J Pediatr Endocrinol. 2014;2014:16.

35. Napierala D, Sam K, Morello R, Zheng Q, Munivez E, Shivdasani RA, et al. Uncoupling of chondrocyte differentiation and perichondrial mineralization underlies the skeletal dysplasia in tricho-rhino-phalangeal syndrome. Hum Mol Genet. 2008;17:2244-54.

36. Momeni P, Glockner G, Schmidt O, von Holtum D, Albrecht B, GillessenKaesbach $\mathrm{G}$, et al. Mutations in a new gene, encoding a zinc-finger protein, cause tricho-rhino-phalangeal syndrome type I. Nat Genet. 2000;24:71-4.

37. Ludecke HJ, Schaper J, Meinecke P, Momeni P, Gross S, von Holtum D, et al. Genotypic and phenotypic spectrum in tricho-rhino-phalangeal syndrome types I and III. Am J Hum Genet. 2001;68:81-91.

38. Hatamura I, Kanauchi Y, Takahara M, Fujiwara M, Muragaki Y, Ooshima A, et al. A nonsense mutation in TRPS1 in a Japanese family with trichorhino-phalangeal syndrome type I. Clin Genet. 2001;59:366-7.

\section{Publisher's Note}

Springer Nature remains neutral with regard to jurisdictional claims in published maps and institutional affiliations.
Ready to submit your research? Choose BMC and benefit from:

- fast, convenient online submission

- thorough peer review by experienced researchers in your field

- rapid publication on acceptance

- support for research data, including large and complex data types

- gold Open Access which fosters wider collaboration and increased citations

- maximum visibility for your research: over $100 \mathrm{M}$ website views per year

At $\mathrm{BMC}$, research is always in progress.

Learn more biomedcentral.com/submissions 